\title{
Fertilidade do Solo sob Sistemas de Produção de Subsistência, Agrofloresta e Vegetação Remanescente em Esperantina - Tocantins
}

\author{
Leonardo Santos Collier ${ }^{1}$, Gelma da Penha Araújo ${ }^{2}$ \\ ${ }^{1}$ Centro Universitário de Gurupi, Universidade Federal do Tocantins - UFT
}

${ }^{2}$ Universidade Federal do Tocantins - UFT

\begin{abstract}
RESUMO
Estudo em Esperantina (TO) quantificou os atributos da fertilidade do solo em área cultivada sob sistema agroflorestal (SAF), mata nativa e lavoura de subsistência. O solo e a serapilheira foram coletados no período chuvoso e no período seco, com 10 repetições. Os teores de nutrientes nas duas épocas foram muito baixos, sendo maiores no solo cultivado com arroz e milho em função da queimada e resíduos de adubação mineral. Os teores de matéria orgânica no SAF se equipararam aos da mata. A serapilheira encontrada no SAF nas duas épocas contrasta com os baixos níveis de nutrientes, podendo contribuir para a manutenção da capacidade produtiva do agroecossistema.
\end{abstract}

Palavras-chave: agrofloresta, ciclagem de nutrientes, serapilheira.

\section{Soil Fertility on Subsistence Production System, Agroforestry and Remaining Vegetation in Esperantina, State of Tocantins, Brazil}

\begin{abstract}
In this work, which was carried out in Esperantina, State of Tocantins, soil fertility parameters were measured in an area cultivated through agroforestry, subsistence farming and native tropical vegetation. Soil and litter were collected in rainy and in dry season with 10 replicates. Nutrient levels were very low in both seasons. Rice and maize cultivation areas presented the highest levels, possibly due to burn practice and mineral fertilizer residues. Organic matter levels of SAF were the same as those of native tropical forest vegetation. The litter obtained on SAF in both seasons contrasts with the low nutrients levels obtained, what could contribute to the maintenance of the production capacity of the agroecosystem.
\end{abstract}

Keywords: agroforestry, nutrients cycling, litter. 


\section{INTRODUÇÃO}

$\mathrm{O}$ atual modelo de cultivo do solo empregado na agricultura enfrenta desafios, principalmente em relação à sustentabilidade do sistema de manejo. A adoção das práticas oriundas da Revolução Verde (pacotes tecnológicos) conduziu, principalmente, ao desequilíbrio ambiental (Martins et al., 1990). Como exemplo desse processo está a ocupação da região Amazônica. Em 1998, havia na Amazônia Legal 55,8 milhões de hectares de terras exploráveis não exploradas. Segundo os dados do INPE (Instituto Nacional de Pesquisa Espacial), de 1998 até 2007, foram desflorestados na região 54,5 milhões de hectares (terras inexploráveis que se tornaram exploráveis) e, entre 1996 e 2006, a área total de lavouras e de pastagens na Amazônia Legal cresceu 23 milhões de hectares, dos quais $45 \%$ relativos a pastagens (Girardi, 2009). Apesar desta expansão estar ligada à atividade pecuária, segundo Sawyer (2001) apud APA (2002), existe cerca de um milhão de famílias de pequenos produtores. Caso cada família desmate cerca de dois hectares por ano, haverá uma contribuição de dois milhões de hectares de área desmatada por ano, ou seja, $20 \mathrm{mil} \mathrm{\textrm {km } ^ { 2 }}$ de vegetação a menos a cada ano. Nestes locais, se estabelece a agricultura migratória marcada pela rotação de pequenas áreas, cultivadas por 2 a 4 anos e intercaladas por longos períodos de descanso (10 a 20 anos), com produtividade decrescente (Götsch, 1996). Além disso, as melhores áreas foram aos poucos destinadas à implantação das monoculturas e pastagens. A forma de cultivo do solo conhecida como processo de "derruba e queima" é agravada pela falta de crédito e de assistência técnica adequada para estes agricultores, levando ao esgotamento dos recursos naturais, entre estes o solo.

O solo em áreas sob vegetação de transição, como o que ocorre na região de estudo, é bem semelhante aos solos de algumas regióes da Amazônia, apresentando $\mathrm{pH}$ baixo, pequena capacidade de troca catiônica e baixa saturação de bases, características que se agravam devido ao processo de lixiviação que ocorre nesses tipos de solos, principalmente por apresentar altos índices pluviométricos, o que pode auxiliar na perda dos nutrientes por lixiviação (Ferreira et al., 2001). Apesar de sua baixa fertilidade, o ambiente de menor interferência agrícola é ocupado por uma vegetação bastante exuberante com árvores altas de troncos eretos sob solos submetidos a chuvas constantes durante praticamente seis meses do ano. A manutenção dessas florestas depende fortemente do processo de ciclagem de nutrientes (Gama Rodrigues, 2004) através das raízes das árvores, retornando nutrientes à superfície na forma de serapilheira (Ribaski et al., 2001). A evidência dessa capacidade é confirmada nos trabalhos de Magalhães e Blum (2000) e Ferreira et al. (1995), observando espécies nativas e exóticas que atingem sempre valores superiores a $1,20 \mathrm{~m}$ de profundidade. A reciclagem de nutrientes é prejudicada quando se remove a cobertura florestal para cultivo de grãos e pastagem, o que ocorre nas áreas de expansão agrícola, como é o caso do norte do Estado do Tocantins.

A crescente preocupação com as questões ambientais e os impactos oriundos dos plantios tecnificados têm conduzido ao retorno das práticas menos agressivas de cultivo do solo. Dentre elas, o sistema agroflorestal tem sido uma alternativa utilizada inicialmente no norte do País consorciando plantios florestais, introduzindo espécies anuais nos primeiros anos, seguidas de frutíferas semiperenes e, por fim, as madeiráveis, que ainda podem ser consorciados com animais, aliando a produção e a conservação dos recursos florestais. Por formar uma estrutura semelhante à da vegetação natural (Leão \& Engel, 2004; Gama Rodrigues, 2004; Gomes et al., 2000), a existência do componente arbóreo traz inúmeros efeitos positivos sobre a fertilidade do solo, controle da erosão e reciclagem de nutrientes (Silva, 2002). Esta é uma alternativa que visa à melhoria da qualidade produtiva do solo, em que cultivos anuais crescem juntamente com os componentes arbóreos na mesma área e ainda podem ser consorciados animais organizados no mesmo espaço e/ou tempo. As áreas que utilizam SAFs provavelmente são mais sustentáveis que áreas de monoculturas, porque apresentam maior diversidade de espécies, à semelhança das florestas, mantendo a fertilidade do solo através da ciclagem de nutrientes. No entanto, faltam informações sobre melhoria da fertilidade do solo pela adoção desses sistemas na região norte do Tocantins. O objetivo deste trabalho foi verificar a fertilidade do solo sob sistema agroflorestal, quando 
comparada à de um sistema natural de mata nativa e de um sistema de lavoura de subsistência.

\section{MATERIAL E MÉTODOS}

O estudo foi realizado entre os meses de março e setembro de 2005 em uma propriedade rural no projeto de assentamento denominado PA Tobata, localizado a seis quilômetros do município de Esperantina-TO a $5^{\circ} 22^{\prime} 30^{\prime \prime} \mathrm{S}$ e $48^{\circ} 37^{\prime} 30^{\prime \prime} \mathrm{W}$. A região apresenta clima úmido, com pequena deficiência hídrica, vegetação classificada como Floresta Ombrófila Aberta, que representa uma área de transição entre floresta Amazônica e Cerrado, em que há diminuição gradativa da densidade de recobrimento. Registram-se temperaturas elevadas, com médias anuais de $28{ }^{\circ} \mathrm{C}$, com solos de baixa fertilidade e ácidos (Secretaria do Planejamento e Meio Ambiente, 1999). O solo da área era um Neossolo Quartzarênico órtico (Empresa..., 1999, 1999) com $11 \%$ de argila.

A propriedade selecionada apresentava uma área com sistema agroflorestal (SAF), uma vegetação remanescente de floresta, e uma área com lavoura de subsistência. O SAF era caracterizado pelo consórcio das espécies Orbignya speciosa (palmeira nativa conhecida como babaçu), Theobroma grandiflorum (cupuaçu), Citrus limonum (limão) e Malpighia emarginata (acerola). A área remanescente apresentava espécies vegetais tanto do tipo cocal (babaçu, inajá e outras palmáceas) como cipoal (com ocorrência do amarelão - Apuleia molaris, ucuuba - Virola spp., e o morototó Dydimopanax morototoni). A área da lavoura media aproximadamente um hectare e apresentava restos culturais de arroz e milho. No período da coleta havia a cultura da mandioca. Na área do SAF, o produtor já utilizou lavoura de subsistência (arroz, feijão-caupi e mandioca) nas entrelinhas, nos três primeiros anos de implantação. Nas áreas de lavoura, houve adubação mineral, mas não foi possível quantificar a dose nem a fórmula NPK empregada. A prática da queimada, quando não existe a cultura da mandioca, é comum na área para facilitar a limpeza do mato.

Foi utilizado um delineamento inteiramente casualizado (os pontos de coleta foram designados por processo aleatório em áreas de mesmo tamanho) com dez repetições para as análises de solos e quatro repetições para a produção de serapilheira, e os tratamentos estudados foram:

1) Sistema Agroflorestal, caracterizado pelo consórcio de árvores nativas, palmeira babaçu, e espécies frutíferas, cupuaçu, limão e acerola.

2) Área de Mata Nativa, (utilizada como testemunha), com aproximadamente 11 ha, com árvores de grande porte, contemplando espécies nativas da região.

3) Área de Lavoura de Subsistência, plantada há 2 anos consecutivos com arroz (Oryza sativa), milho (Zea mays) e mandioca (Manihot sculenta Crantz)

Em março de 2005, foi realizada a primeira coleta de solo, correspondendo ao período chuvoso, em três profundidades: 0-10, 10-20 e 20-40 cm, com 10 repetições. O solo foi seco ao ar, peneirado e levado ao laboratório para determinação do $\mathrm{pH}(\mathrm{em} \mathrm{CaCl})$, $\mathrm{P}$ e K (Mehlich-1), Ca, $\mathrm{Mg}$ e $\mathrm{Al}(\mathrm{KCl} 1,0 \mathrm{~mol} / \mathrm{L})$ $\mathrm{H}+\mathrm{Al}$ (acidez potencial), matéria orgânica (Carbono orgânico) conforme Embrapa (Empresa..., 1997).

Foi coletada também a serapilheira dos três sistemas estudados. Em cada sistema, foram escolhidos quatros pontos aleatoriamente e coletada a serapilheira de uma área de $1 \mathrm{~m}^{2}$. O material foi acondicionado em saco de papel e posteriormente seco e pesado, verificando-se estimativa de produção de matéria seca por hectare. $\mathrm{O}$ mesmo procedimento foi realizado em setembro de 2005, correspondendo aos dados obtidos no período seco. Os resultados obtidos foram submetidos à análise de variância e as respectivas médias comparadas pelo teste de Tukey a $5 \%$ de probabilidade.

\section{RESULTADOS E DISCUSSÃO}

No período chuvoso os valores de $\mathrm{pH}$ nas áreas estudadas variaram de 3,5 a 4,1 com valores mais altos no SAF e na lavoura, do que na mata na primeira camada (Tabela 1). No período seco, os valores de $\mathrm{pH}$ no sistema agroflorestal (SAF) não apresentaram diferença significativa em relação à lavoura e a mata. As medidas de $\mathrm{pH}$ não apresentaram muita variação entre as camadas, embora fosse verificado que o solo tende à acidificação nas camadas mais profundas. Moreira \& Costa (2004) observaram uma diminuição do $\mathrm{pH}$ do solo em profundidade em áreas reflorestadas 
da Amazônia. Porém, estes resultados diferem dos de Ferreira et al. (2001), que observaram que em áreas de fragmentação de floresta em Latossolo Amarelo álico ocorreu um aumento do $\mathrm{pH}$ em profundidade. $\mathrm{O}$ sistema de mata não apresentou variação do $\mathrm{pH}$ nas diferentes camadas, tanto no período seco como no chuvoso, provavelmente o poder tampão matéria orgânica presente possibilitou a maior estabilidade do sistema. Segundo Primavesi (1994), a matéria orgânica humificada em solos ácidos contribui para a formação de $\mathrm{pH}$ mais favorável às plantas. Em relação ao $\mathrm{pH}$ do solo, o SAF assemelha-se mais à mata em termos de estabilidade do $\mathrm{pH}$ ao longo das camadas, diminuindo a tendência à acidificação dos solos cultivados.

Considerando a acidez trocável, houve teores menores de $\mathrm{Al}$ na área de lavoura em relação aos outros sistemas na avaliação geral do estudo (Tabela 2). O sistema de lavoura apresentou maior tendência a incremento do $\mathrm{Al}$ ao longo das camadas, atingindo valores semelhantemente ao sistema de mata.

O teor de alumínio (Al) no período chuvoso foi mais elevado no SAF e na mata e bastante reduzido na área de lavoura (Tabela 2). Porém, no período seco não houve diferença significativa entre os sistemas, na primeira camada. No período seco, houve maior acúmulo de $\mathrm{Al}$ em profundidade no SAF, resultados semelhantes aos encontrados por Marques et al. (2004). Os demais sistemas apresentaram a mesma tendência de acumular alumínio em profundidade.

Os valores mais elevados no SAF nas diferentes profundidades e ao longo das duas épocas sugerem limitação ao desenvolvimento das espécies cultivadas. No entanto, trabalhos como o de Bernardes et al. (2000) verificaram que o solo de um sistema agroflorestal, após 16 anos da sua implantação, havia recuperado os teores de matéria orgânica e a CTC semelhantes aos encontrados na cobertura original (floresta). Desta forma, a cobertura vegetal encontrada no SAF pode ter conseguido disponibilizar maior quantidade de nutrientes e isso pode afetar o teor de $\mathrm{Al}$ e torná-lo menos tóxico. As espécies frutíferas de cupuaçu, limão e acerola utilizadas podem levar a subcamada a uma elevação nos níveis de Al pela extração de cátions básicos para formação de frutos. Trabalho de Correia \& Durigan (2008) também encontra maior acidificação do solo quando resíduos são adicionados em relação à

Tabela 1. Variação do $\mathrm{pH}$ em $\mathrm{CaCl}_{2}$ do solo avaliado nos sistemas de manejo estudados em três profundidades, em dois períodos do ano, no município de Esperantina-TO.

Table 1. Variation of soil $\mathrm{pH}$ in $\mathrm{CaCl}_{2}$ measured in the cropping systems studied at three dephts, in two seasons, in the municipality of Esperantina, TO.

\begin{tabular}{|c|c|c|c|c|c|c|}
\hline \multirow{2}{*}{ Tratamentos } & \multirow{2}{*}{ Geral } & \multicolumn{3}{|c|}{ Profundidade } & \multicolumn{2}{|c|}{ Época } \\
\hline & & $0-10 \mathrm{~cm}$ & $10-20 \mathrm{~cm}$ & $20-40 \mathrm{~cm}$ & Chuvosa & Seca \\
\hline Mata & $3,82^{\mathrm{c}}$ & $3,75^{\mathrm{cA}}$ & $3,85^{\mathrm{bA}}$ & $3,85^{\mathrm{aA}}$ & $3,63^{\mathrm{aB}}$ & $4,00^{\mathrm{aA}}$ \\
\hline SAF & $4,03^{b}$ & $4,05^{\mathrm{bA}}$ & $4,05^{\mathrm{aA}}$ & $4,00^{\mathrm{aA}}$ & $4,03^{\mathrm{aA}}$ & $4,03^{\mathrm{aA}}$ \\
\hline Lavoura & $4,17^{\mathrm{a}}$ & $4,40^{\mathrm{aA}}$ & $4,05^{\mathrm{aA}}$ & $4,05^{\mathrm{aB}}$ & $4,17^{\mathrm{aA}}$ & $4,17^{\mathrm{aA}}$ \\
\hline $\mathrm{CV}$ & $7,27 \%$ & & & & & \\
\hline
\end{tabular}

Médias seguidas da mesma letra minúscula na coluna e maiúscula na linha não diferem entre si pelo teste Scott-Knot $(\mathrm{p}<0,05)$.

Tabela 2. Variação do teor de Al trocável do solo (em $\mathrm{mmol}_{\mathrm{c}} \mathrm{dm}^{-3}$ solo) avaliado nos sistemas de manejo estudados em três profundidades, em dois períodos do ano, no município de Esperantina-TO.

Table 2. Variation in soil exchangeable Al levels (in $\mathrm{mmol}_{\mathrm{c}} \mathrm{dm}^{-3}$ ) measured in the cropping systems studied at three dephts, in two seasons, in the municipality of Esperantina, TO.

\begin{tabular}{|c|c|c|c|c|c|c|}
\hline \multirow{2}{*}{ Tratamentos } & \multirow{2}{*}{ Geral } & \multicolumn{3}{|c|}{ Profundidade } & \multicolumn{2}{|c|}{ Época } \\
\hline & & $0-10 \mathrm{~cm}$ & $10-20 \mathrm{~cm}$ & $20-40 \mathrm{~cm}$ & Chuvosa & Seca \\
\hline Mata & $10,0^{\mathrm{b}}$ & $10,0^{\mathrm{aA}}$ & $10,2^{\mathrm{bA}}$ & $10,1^{\mathrm{bA}}$ & $9,6^{\mathrm{bA}}$ & $10,5^{\mathrm{aA}}$ \\
\hline SAF & $11,8^{\mathrm{a}}$ & $9,8^{\mathrm{aB}}$ & $12,4^{\mathrm{aA}}$ & $13,2^{\mathrm{aA}}$ & $12,2^{\mathrm{aA}}$ & $11,4^{\mathrm{aA}}$ \\
\hline Lavoura & $8,6^{c}$ & $5,1^{\mathrm{bB}}$ & $10,0^{\mathrm{bA}}$ & $10,8^{\mathrm{bA}}$ & $8,3^{\mathrm{bA}}$ & $8,9^{\mathrm{bA}}$ \\
\hline $\mathrm{CV}$ & $35,2 \%$ & & & & & \\
\hline
\end{tabular}

Médias seguidas da mesma letra minúscula na coluna e maiúscula na linha não diferem entre si pelo teste Scott-Knot $(\mathrm{p}<0,05)$. 
vegetação espontânea, fato que também pode estar ocorrendo na área em estudo.

Os valores de $\mathrm{H}+\mathrm{Al}$ foram mais elevados no SAF, seguidos da mata e depois lavoura no SAF, enquanto que na lavoura apresentou valor mais baixo. Acredita-se que a adição de resíduos vegetais com alta velocidade de decomposição em solos arenosos (Rheinheimer et al., 1998), o que ocorre praticamente o ano todo no SAF, pode levar a maior acidificação do solo. Essa acidificação persiste em profundidade pela possível mobilidade das substâncias húmicas no perfil (Ceretta, 1995; Martin Neto, 1994 apud Rheinheimer et al., 1998)

Mesmo com menor acidificação, a área de lavoura não apresenta redução em profundidade como ocorreu nas áreas de SAF e mata. A maior atividade biológica nas camadas superficiais desses dois sistemas pode estar relacionada à maior acidificação até $20 \mathrm{~cm}$ de profundidade. A área de mata apresentou em profundidade de 20-40 cm (Nye, 1961) níveis de acidez potencial inferiores aos dos outros sistemas, confirmando a tendência observada para o $\mathrm{pH}$ e Al trocável e de acordo com trabalho de Correia \& Durigan (2008), que obtiveram maior acidificação quando empregaram resíduos vegetais distintos da vegetação espontânea.

$\mathrm{Na}$ avaliação do efeito da época de observação, para o SAF e a lavoura, o período de estiagem apresenta níveis de acidez mais elevados (Tabela 3), possivelmente pela maior remoção dos cátions básicos pelas culturas e pelo processo de reacidificação do solo após o período chuvoso (Alleoni et al., 2009). O comportamento da mata é diferente, o que pode ser compreendido por uma exportação menor durante o período chuvoso (melhor distribuída pela maior diversidade de espécies e seu respectivo nível de exigência nutricional) e a redução do crescimento no período seco e reciclagem de material da serrapilheira equilibrando as espécies químicas, o que promove menor acidificação nesse período.

Em relação ao teor de $\mathrm{Ca}+\mathrm{Mg}$ (Tabela 4), os valores mais expressivos foram encontrados na mata e na lavoura. $\mathrm{O}$ uso do fogo pode ajudar a manter os níveis de $\mathrm{Ca}+\mathrm{Mg}$, sendo que no $\mathrm{SAF}$, em que não há fogo pela presença do cupuaçu, a extração da cultura sem uma devida reposição pode ser a causa de níveis baixos.

A avaliação em profundidade pode ajudar a explicar o argumento anterior quando o SAF

Tabela 3. Variação do teor de $\mathrm{H}+\mathrm{Al}$ do solo (acidez potencial em $\mathrm{mmol}_{\mathrm{c}} \mathrm{dm}^{-3} \mathrm{solo}$ ) avaliado nos sistemas de manejo estudados em três profundidades, em dois períodos do ano, no município de Esperantina-TO.

Table 3. Variation in soil $\mathrm{H}+\mathrm{Al}$ levels (potencial acidity in $\mathrm{mmol}_{\mathrm{c}} \mathrm{dm}^{-3}$ ) measured in the cropping systems studied at three dephts, in two seasons, in the municipality of Esperantina, TO.

\begin{tabular}{|c|c|c|c|c|c|c|}
\hline \multirow{2}{*}{ Tratamentos } & \multirow{2}{*}{ Geral } & \multicolumn{3}{|c|}{ Profundidade } & \multicolumn{2}{|c|}{ Época } \\
\hline & & $0-10 \mathrm{~cm}$ & $10-20 \mathrm{~cm}$ & $20-40 \mathrm{~cm}$ & Chuvosa & Seca \\
\hline Mata & $41,0^{c}$ & $43,6^{\mathrm{bA}}$ & $44,0^{\mathrm{cA}}$ & $35,6^{\mathrm{bB}}$ & $36,2^{\mathrm{bB}}$ & $45,9^{\mathrm{bA}}$ \\
\hline SAF & $61,5^{\mathrm{a}}$ & $69,2^{\text {aA }}$ & $62,3^{\mathrm{aA}}$ & $53,1^{\mathrm{aB}}$ & $54,0^{\mathrm{aB}}$ & $69,0^{\mathrm{aA}}$ \\
\hline Lavoura & $51,1^{\mathrm{b}}$ & $50,5^{\mathrm{bA}}$ & $52,6^{\mathrm{bA}}$ & $50,3^{\text {aA }}$ & $38,3^{\text {bB }}$ & $63,9^{\mathrm{aA}}$ \\
\hline $\mathrm{CV}$ & $25,2 \%$ & & & & & \\
\hline
\end{tabular}

Médias seguidas da mesma letra minúscula na coluna e maiúscula na linha não diferem entre si pelo teste $\operatorname{Scott-Knot~}(\mathrm{p}<0,05)$.

Tabela 4. Variação do teor de Ca+Mg trocáveis do solo (em $\mathrm{mmol}_{\mathrm{c}} \mathrm{dm}^{-3}$ solo) avaliados nos sistemas de manejo estudados em três profundidades, em dois períodos do ano, no município de Esperantina-TO.

Table 4. Variation in soil exchangeable $\mathrm{Ca}+\mathrm{Mg}\left(\right.$ in $\mathrm{mmol} \mathrm{dm}_{\mathrm{c}}^{-3}$ ) measured in the cropping systems studied at three dephts, in two seasons, in the municipality of Esperantina, TO.

\begin{tabular}{ccccccc}
\multirow{2}{*}{ Tratamentos } & Geral & \multicolumn{3}{c}{ Profundidade } & \multicolumn{2}{c}{ Época } \\
\cline { 3 - 7 } & & $\mathbf{0 - 1 0} \mathbf{~ c m}$ & $\mathbf{1 0 - 2 0} \mathbf{~ c m}$ & $\mathbf{2 0 - 4 0} \mathbf{~ c m}$ & Chuvosa & Seca \\
Mata & $27,6^{\mathrm{a}}$ & $36,9^{\mathrm{aA}}$ & $25,1^{\mathrm{aB}}$ & $20,8^{\mathrm{aB}}$ & $31,3^{\mathrm{aA}}$ & $23,9^{\mathrm{aB}}$ \\
SAF & $14,1^{\mathrm{b}}$ & $18,5^{\mathrm{cA}}$ & $12,4^{\mathrm{bA}}$ & $11,3^{\mathrm{bA}}$ & $11,1^{\mathrm{bA}}$ & $17,1^{\mathrm{aA}}$ \\
Lavoura & $24,6^{\mathrm{a}}$ & $27,9^{\mathrm{bA}}$ & $23,3^{\mathrm{aA}}$ & $22,7^{\mathrm{aA}}$ & $30,3^{\mathrm{aA}}$ & $18,9^{\mathrm{aB}}$ \\
CV & $54,4 \%$ & & & & \\
\hline
\end{tabular}

Médias seguidas da mesma letra minúscula na coluna e maiúscula na linha não diferem entre si pelo teste $\operatorname{Scott-Knot~}(\mathrm{p}<0,05)$. 
apresenta os menores níveis de $\mathrm{Ca}+\mathrm{Mg}$ e a mata os mais elevados. Isso demonstra a importância da serrapilheira no fornecimento de nutrientes na área da mata. A área de lavoura tem teores que não variam em profundidade possivelmente pela aração e gradagem que é realizada eventualmente.

A avaliação da época de amostragem indicou a mata e a lavoura com uma redução de $\mathrm{Ca}+\mathrm{Mg}$ do período chuvoso para o seco. Essa tendência não se manteve para o SAF que, embora apresentasse níveis baixos e sem diferença significativa, poderia significar maior reciclagem desses nutrientes, no período seco, associada a menor exportação de nutrientes para frutos.

O fato de existir a prática da queimada e da adubação química na área da lavoura deve ser considerado na avaliação dos sistemas estudados no ciclo proposto como contribuição aos níveis de $\mathrm{Ca}+\mathrm{Mg}$ obtidos.

A área de lavoura apresentou os maiores teores de potássio trocável, seguida pelo SAF e depois pela mata (Tabela 5). Conhecendo os teores normalmente obtidos em solos arenosos do ambiente Amazônico (Instituto..., 2003), percebe-se que as áreas de SAF e lavoura podem ter recebido algum insumo ou há restituição de K por algum resíduo cultural. Santos (2003) mostrou o efeito favorável da utilização do resíduo da casca de cupuaçu como fonte de $\mathrm{K}$ para as plantas de cupuaçu em consórcios agroflorestais do Projeto RECA no Acre. Vital et al. (2004) verificaram que o $\mathrm{K}$ é um dos elementos mais exportados nas colheitas pelo cupuaçu, principalmente através das cascas.

A avaliação em profundidade (Tabela 5) demonstra que a área com lavoura apresenta os maiores níveis de $\mathrm{K}$ nos três extratos avaliados. Isso denota o uso de adubação química associada à queimada eventual.

Com uma tendência distinta do $\mathrm{Ca}+\mathrm{Mg}$, nos três sistemas, ocorre uma redução dos níveis de $\mathrm{K}$ no período seco (Tabela 5). Essa redução está relacionada à extração pelas culturas e pelo comportamento de menor afinidade com os resíduos orgânicos (Ernani et al., 2007) em transformação estando mais sujeito a perdas no solo.

A utilização da cultura do cupuaçu no SAF pode estar associada ao baixo teor desse nutriente na última camada, uma vez que, Ayres \& Alfaia (2007) confirmam sua demanda em sistemas agroflorestais do Acre. A reposição deste elemento provavelmente é realizada através da deposição da serapilheira.

O teor de $\mathrm{P}$ encontrado na mata superou o SAF e a lavoura, sem diferença entre estes dois (Tabela 6). Esses valores para tabelas de recomendação de adubação de algumas culturas perenes poderiam suprir a demanda inicial delas (Alfaia \& Ayres, 2004). A proximidade da região com o encontro das duas bacias - Araguaia e Tocantins (Instituto..., 2003) pode representar aporte de sedimentos que podem conter P. O fato da mata apresentar níveis de $\mathrm{P}$ mais elevados pode representar menores perdas e menores extrações do elemento que pode ter contribuição dos resíduos vegetais na serrapilheira mais diversificada. Quando se observa o comportamento dos níveis de $\mathrm{P}$ da mata nas duas épocas, percebe-se a relação com atividade biológica, que é mais intensa no período chuvoso, e sugerindo interferência dessa biota na dinâmica de $\mathrm{P}$.

Embora o SAF também seja um sistema em que ocorre adição de fertilizantes, a cultura

Tabela 5. Variação do teor de $\mathrm{K}$ trocável do solo incluir (em mg.dm ${ }^{-3}$ ) com o -3 sobrescrito (igual ao da tabela 6 entre parênteses).

Table 5. Variation in soil exchangeable K (in mg.dm ${ }^{-3}$ ) measured in the cropping systems studied at three dephts, in two seasons, in the municipality of Esperantina, TO.

\begin{tabular}{|c|c|c|c|c|c|c|}
\hline \multirow{2}{*}{ Tratamentos } & \multirow{2}{*}{ Geral } & \multicolumn{3}{|c|}{ Profundidade } & \multicolumn{2}{|c|}{ Época } \\
\hline & & $0-10 \mathrm{~cm}$ & $10-20 \mathrm{~cm}$ & $20-40 \mathrm{~cm}$ & Chuvosa & Seca \\
\hline Mata & $21,8^{c}$ & $34,3^{\mathrm{cA}}$ & $20,3^{\mathrm{bB}}$ & $10,7^{\mathrm{bC}}$ & $26,3^{\mathrm{cA}}$ & $17,2^{\mathrm{bB}}$ \\
\hline SAF & $28,6^{\mathrm{b}}$ & $46,0^{\mathrm{bA}}$ & $24,8^{\mathrm{bB}}$ & $15,2^{\mathrm{bC}}$ & $37,8^{\mathrm{bA}}$ & $19,5^{\mathrm{bB}}$ \\
\hline Lavoura & $44,9^{\mathrm{a}}$ & $59,0^{\mathrm{aA}}$ & $41,0^{\mathrm{aB}}$ & $34,7^{\mathrm{aB}}$ & $56,2^{\mathrm{aA}}$ & $33,6^{\mathrm{aB}}$ \\
\hline $\mathrm{CV}$ & $41,9 \%$ & & & & & \\
\hline
\end{tabular}

Médias seguidas da mesma letra minúscula na coluna e maiúscula na linha não diferem entre si pelo teste Scott-Knot $(\mathrm{p}<0,05)$. 
predominante foi o cupuaçu segundo Alfaia \& Ayres (2004), que, estudando o efeito da adubação em cultivares de cupuaçu, puderam observar uma elevada concentração de $\mathrm{P}$ nas folhas mostrando a absorção do fósforo por esta cultura.

Assim, a utilização da cultura do cupuaçu poderia supostamente significar um maior aporte de fósforo para as plantas que retornaria ao solo pela serrapilheira, fornecendo este nutriente para o sistema. Embora a lavoura tenha teores de P e comportamento ao longo das profundidades estudadas semelhante à mata, o uso do fogo e da adubação química pode explicar os valores, mesmo sabendo que também possa ocorrer contribuição de atividade biológica a partir dos resíduos dessas culturas (Tabela 8) e do revolvimento do solo.

O teor de matéria orgânica não apresentou diferença significativa entre as áreas e também entre estas nos dois períodos de estudo com exceção da área de lavoura (Tabela 7). Entre as diferentes profundidades estudadas também não ocorreu diferença significativa, mas em valores absolutos registrou-se discreto incremento de matéria orgânica da camada superficial para a camada de 20-40 cm em todos os sistemas estudados (Tabela 7). Devido ao alto teor de areia, a camada de maior revolvimento possivelmente perde mais carbono do que as subcamadas, além destas poderem receber compostos de carbono de maior mobilidade das camadas superficiais (Santos et al., 2008).

O teor de matéria orgânica nos sistemas estudados demonstra que o sistema agroflorestal manteve valores semelhantes aos da mata, considerada a testemunha neste tratamento. A maior deposição de serapilheira encontrada no SAF entre os períodos de março e setembro é um forte indicativo de que este sistema tende a contribuir para o fornecimento de matéria orgânica e ciclagem de nutrientes.

Os valores de matéria orgânica da área cultivada com lavoura no período da seca chamam atenção para a contribuição dos resíduos vegetais do sistema de cultivo (Tabela 8) ser capaz de representar aportes de matéria orgânica equivalentes aos outros sistemas, embora se esperasse o contrário.

Tabela 6. Variação do teor de P assimilável do solo (em mg.dm ${ }^{-3}$ de solo) avaliado nos sistemas de manejo estudados em três profundidades, em dois períodos do ano, no município de Esperantina, TO.

Tabela 6. Variation on soil assimilated P (in mg.dm ${ }^{-3}$ ) measured in the cropping systems studied at three dephts, in two seasons, in the municipality of Esperantina, TO.

\begin{tabular}{|c|c|c|c|c|c|c|}
\hline \multirow{2}{*}{ Tratamentos } & \multirow{2}{*}{ Geral } & \multicolumn{3}{|c|}{ Profundidade } & \multicolumn{2}{|c|}{ Época } \\
\hline & & $0-10 \mathrm{~cm}$ & $10-20 \mathrm{~cm}$ & $20-40 \mathrm{~cm}$ & Chuvosa & Seca \\
\hline Mata & $7,1^{\mathrm{a}}$ & $10,7^{\mathrm{aA}}$ & $7,1^{\mathrm{aB}}$ & $3,4^{\mathrm{aC}}$ & $11,2^{\mathrm{aA}}$ & $2,9^{\mathrm{bB}}$ \\
\hline SAF & $4,3^{\mathrm{b}}$ & $7,4^{\mathrm{bA}}$ & $3,5^{\mathrm{bB}}$ & $2,0^{\mathrm{aB}}$ & $5,5^{\mathrm{bA}}$ & $3,1^{\mathrm{bB}}$ \\
\hline Lavoura & $5,3^{\mathrm{b}}$ & $9,6^{\mathrm{aA}}$ & $4,1^{\mathrm{bB}}$ & $3,4^{\mathrm{aB}}$ & $5,1^{\mathrm{bA}}$ & $5,6^{\mathrm{aA}}$ \\
\hline $\mathrm{CV}$ & $77,4 \%$ & & & & & \\
\hline
\end{tabular}

Médias seguidas da mesma letra minúscula na coluna e maiúscula na linha não diferem entre si pelo teste Scott-Knot $(\mathrm{p}<0,05)$.

Tabela 7. Variação do teor de matéria orgânica (em g. $\mathrm{kg}^{-1}$ ), a partir do carbono orgânico oxidável) do solo avaliado nos sistemas de manejo estudados em três profundidades, em dois períodos do ano, no município de Esperantina, TO.

Table 7. Variation on soil organic matter (in g. $\mathrm{kg}^{-1}$, obtained by oxidable organic carbon) measured in the cropping systems studied at three dephts, in two seasons, in the municipality of Esperantina, TO.

\begin{tabular}{|c|c|c|c|c|c|c|}
\hline \multirow{2}{*}{ Tratamentos } & \multirow{2}{*}{ Geral } & \multicolumn{3}{|c|}{ Profundidade } & \multicolumn{2}{|c|}{ Época } \\
\hline & & $0-10 \mathrm{~cm}$ & $10-20 \mathrm{~cm}$ & $20-40 \mathrm{~cm}$ & Chuvosa & Seca \\
\hline Mata & $17,45^{\mathrm{a}}$ & $16,50^{\mathrm{aC}}$ & $17,50^{\mathrm{aB}}$ & $18,35^{\mathrm{aA}}$ & $18,0^{\mathrm{aA}}$ & $17,6^{\mathrm{aA}}$ \\
\hline SAF & $17,82^{\mathrm{a}}$ & $16,90^{\mathrm{aB}}$ & $17,55^{\mathrm{aB}}$ & $19,00^{\text {aA }}$ & $17,8^{\mathrm{aA}}$ & $17,1^{\mathrm{bA}}$ \\
\hline Lavoura & $17,75^{\mathrm{a}}$ & $16,70^{\mathrm{aC}}$ & $17,75^{\mathrm{aB}}$ & $18,80^{\mathrm{aA}}$ & $17,3^{\mathrm{aB}}$ & $18,2^{\mathrm{aA}}$ \\
\hline $\mathrm{CV}$ & $6,45 \%$ & & & & & \\
\hline
\end{tabular}

Médias seguidas da mesma letra minúscula na coluna e maiúscula na linha não diferem entre si pelo teste $\operatorname{Scott-Knot~}(\mathrm{p}<0,05)$. 
Tabela 8. Formação de serapilheira em t.ha ${ }^{-1}$ através do acúmulo de matéria seca, em sistema agroflorestal, mata e lavoura, em dois períodos do ano, no Município de Esperantina, TO.

Table 8. Generation of litter in t.ha ${ }^{-1}$ by dry biomass accumulation, in agroforestry system, secondary forest and cropland, in two seasons of the year, in the municipality of Esperantina, TO.

\begin{tabular}{|c|c|c|}
\hline \multirow{2}{*}{ Tratamentos } & Período chuvoso & Período seco \\
\hline & \multicolumn{2}{|c|}{ t. $h \mathrm{a}^{-1}$} \\
\hline SAF & $1,48^{\mathrm{a}}$ & $4,41^{\mathrm{a}}$ \\
\hline Mata & $1,82^{\mathrm{a}}$ & $3,43^{\mathrm{ab}}$ \\
\hline Lavoura & $2,12^{\mathrm{a}}$ & $2,25^{\mathrm{b}}$ \\
\hline $\mathrm{Cv}$ & 23,64 & 17,07 \\
\hline
\end{tabular}

${ }^{*} \mathrm{Cv}$ : coeficiente de variação. ${ }^{*}$ Os valores representam médias de dez repetições. Médias seguidas da mesma letra, nas colunas, não diferem entre si pelo Teste Tukey $(\mathrm{p}<0,05)$.

Os resíduos de culturas da área de lavoura podem representar uma oferta de carbono expressiva à biota do solo (Zech et al., 1997) devido ao cultivo consorciado e por ter recebido doses de fertilização mineral. De acordo com Anderson \& Spencer (1991), o maior incremento de nutrientes em sistema de florestas pode estar associado à matéria orgânica e às reservas de matéria seca provenientes da serapilheira.

A formação da serapilheira avaliada pelo acúmulo da matéria seca foi maior no sistema de lavoura no período chuvoso seguida pela mata e SAF, respectivamente (Tabela 8). Porém, não houve diferença significativa entre os sistemas analisados.

No período seco, houve diferença significativa para o acúmulo de matéria seca serapilheira da mata e do SAF, porém nota-se que os valores acumulados de março a setembro são bastante expressivos, pois funcionam como fonte de reserva de resíduos para decomposição e fornecimento de nutrientes pela mineralização da matéria orgânica. A lavoura foi o sistema que apresentou menor média de acúmulo de matéria seca, no período seco em relação ao SAF, possivelmente porque nesse período já ocorreu a colheita da maioria das culturas implantadas e, nesse caso especificamente, havia apenas a cultura da mandioca no sistema que gera pouca deposição de resíduo quando comparada a um sistema que utiliza várias espécies ao mesmo tempo. Porém não ocorreu diferença significativa entre a lavoura e a mata.
O fato de se observar maior formação de serapilheira na lavoura pode estar associado à presença das culturas de ciclo curto implantadas nesse período, que deixaram os restos vegetais logo após a colheita (neste caso, as culturas do arroz e milho que já tinham sido colhidas). A serapilheira contribui para a qualidade da fertilidade do solo e, segundo Vital et al. (2004), parte do processo de retorno de matéria orgânica e de nutrientes para o solo florestal se dá através da produção de serapilheira. Assim, notam-se os benefícios que o SAF apresenta no período seco por apresentar maior formação de serapilheira (Tabela 8). Resultados semelhantes foram apresentados por Luizão \& Schubart (1987), que observaram maior produção de liteira no período menos chuvoso, de junho a outubro, e que a maior parte da decomposição ocorre durante a estação chuvosa. Vital et al. (2004) também encontraram maior acúmulo de serapilheira no final do período seco em floresta semidecidual no Estado de São Paulo. A queda de folhas em florestas tropicais é, de modo geral, contínua, mas variável, apresentando um pico máximo na estação seca (Golley, 1983).

A quantidade de serapilheira na mata e no SAF representa uma fonte de reserva nutricional para vegetação, enquanto que a lavoura tende ao empobrecimento do solo por não haver deposição em quantidade e diversidade para a reposição natural da fertilidade do solo pelo retorno de nutrientes encontrados na matéria orgânica. Segundo Ferreira et al. (2001), em regiões tropicais, as maiores contribuições são dadas pela liteira produzida pela parte aérea da vegetação, e os sistemas de lavoura convencionais acumulam menor quantidade de matéria seca na liteira. Em um estudo no Rio de Janeiro, sobre deposição de serapilheira em mata secundária e áreas de eucalipto, ocorreu maior deposição de serapilheira na estação seca. Esta maior deposição, segundo Corrêa Neto et al. (2001), pode estar relacionada a uma resposta da vegetação ao agravamento do estresse hídrico, sendo determinada a queda de folhas, medida preventiva à alta perda de água por transpiração e sazonalidade de espécies caducifólias. Plantas do Cerrado também apresentam atributos semelhantes para controle da transpiração (Corrêa Neto et al., 2001). Foi observado 
que os resultados tendem a uma menor formação de matéria seca na mata, quando comparados com o SAF, mesmo não havendo diferença significativa entre os sistemas. Sobre esse aspecto, pode-se dizer, segundo Bray \& Ghoran (1964), que há um aumento da deposição da serapilheira até a idade em que as árvores atingem a maturidade ou fecham as suas copas e, após esse ponto, pode ocorrer ligeiro decréscimo ou estabilização. Embora o aporte de serrapilheira na seca seja expressivo no SAF, o mesmo não está se traduzindo em melhoria dos atributos químicos do solo. Assim, como o trabalho de Assis Jr. et al. (2003), que observou altas taxas de evolução de $\mathrm{CO}_{2}$ em sistemas de mata observados no nordeste de Minas Gerais, poderia sugerir que onde houve uma maior cobertura florestal, até mesmo pelo cupuaçu no SAF, significaria transformação microbiana intensa, promovendo liberação de nutrientes que poderiam não ser retidos no solo arenoso em estudo.

\section{CONCLUSÕES}

Considerando os dois períodos de amostragem e as três camadas de solo analisadas, o SAF com seis anos de implantação apresentou valores que sugerem redução nos atributos químicos do solo analisados em laboratório e empregados normalmente para avaliar a fertilidade potencial do solo. O sistema de lavoura apresentou teores mais elevados de P, $\mathrm{K}$, possivelmente por se tratar de uma área recémformada e pelo consórcio entre as culturas reduzir a tendência ao empobrecimento do solo e dependência química para se manter produtivo. Os resultados obtidos nas camadas mais profundas sugerem que, embora ocorra contribuição do sistema radicular e do aporte de resíduos das espécies arbóreas, o manejo do SAF demanda práticas que venham a incrementar os atributos químicos do solo, evitando comprometer a produtividade das culturas e, consequentemente, sua sustentabilidade nos solos da região estudada.

\section{STATUS DA SUBMISSÃO}

Recebido: 07/10/2008
AUTOR(ES) PARA CORRESPONDÊNCIA

\section{Leonardo Santos Collier}

Escola de Agronomia e Engenharia de Alimentos Universidade Federal de Goiás - UFG

CP 131, CEP 74001-970

Campus Samambaia Goiânia, GO, Brasil

e-mail: leouft@gmail.com

\section{Gelma da Penha Araújo \\ Cartório Central \\ CEP 68379-200}

Castelo dos Sonhos, PA, Brasil

e-mail: gelmapenha@hotmail.com

\section{REFERÊNCIAS}

Alfaia SS, Ayres MIC. Efeito de doses de nitrogênio, fósforo e potássio em duas cultivares de cupuaçu com e sem sementes, na região da Amazônia Central. Revista Brasileira de Fruticultura 2004; 26(2):67-73.

Alleoni LRF, Camargo AO, Casagrande JC, Soares MR. Química dos solos altamente intemperizados. In: Melo WF, Alleoni LRF, editores. Química do solo. Viçosa: SBCS; 2009. v. 2, p. 381-447.

Anderson JM, Spencer T. Carbon, nutrient and water balances of tropical rain forest ecossystems subject to disturbance. Paris: UNESCO; 1991.

Assis Jr. SL, Zanuncio JC, Kasuya MCM, Couto R, Melido RCN. Atividade microbiana do solo em sistemas agroflorestais, monoculturas, mata natural e área desmatada. Revista Árvore 2003; 27(1):35-41.

Associação de Produtores Alternativos - APA. Desenvolvimento sustentável para agricultores da Amazônia Ocidental - Fase II. Ouro Preto do Oeste: APA-PD/A; 2002. Relatório de avaliação do Projeto $\mathrm{PD} / \mathrm{A}$.

Ayres MIC, Alfaia SS. Calagem e adubação potássica no cupuaçuzeiro em sistemas agroflorestais da Amazônia Ocidental. Pesquisa Agropecuária Brasileira 2007; 42(7):957-963.

Bernardes MS, Lima SFF, Teramoto ER, Righi CA, Bernardes AS. Recuperação de solo degradado com sistema agroflorestal no extremo Sul da Bahia. In: Resumos Expandidos da XII Reunião Brasileira de Manejo e Conservação do Solo e da Água [CD-ROM]; 2000; Ilhéus. Ilhéus: CEPLAC/CEPEC; 2000.

Bray JR, Ghoran E. Litter production in forest of the world. Advances Ecology of Research 1964; 2:101-157. doi:10.1016/S0065-2504(08)60331-1 
Corrêa Neto TA, Pereira MG, Correa MEF, Anjos LHC. Deposição de serapilheira e mesofauna edáfica em áreas de eucalipto e floresta secundária. Floresta e Ambiente 2001; 8(1):70-75.

Correia MN, Durigan JC. Culturas de cobertura e sua influência na fertilidade do solo sob sistema de plantio direto. Bioscience Journal 2008; 24(4):20-31.

Empresa Brasileira de Pesquisa Agropecuária. Manual de métodos de análises de solos. 2. ed. Rio de Janeiro: EMBRAPA, CNPS; 1997, 212p.

Empresa Brasileira de Pesquisa Agropecuária. Sistema brasileiro de classificação de solos. Brasília: EMBRAPA Serviço de Produção de Informações; 1999.

Ernani PR, Almeida JA, Santos FC. Potássio. In: Novais et al., editor. Fertilidade do solo. Viçosa: SBCS; 2007. 1017 p.

Ferreira SAN, Clement CR, Ranzani G, Costa SS. Contribuição ao conhecimento do sistema radicular da pupunheira (Bactris gassipaes Kunth, Palmae.). II. Solo Latossolo Amarelo, textura argilosa. Acta Amazônica 1995; 25(3/4):161-170.

Ferreira SJF, Crestana S, Luizão FJ, Miranda SAF. Nutrientes no solo em florestas de terra firme cortada seletivamente na Amazônia Central. Acta Amazonica 2001; 31(3):381-396.

Gama Rodrigues AC. Ciclagem de nutrientes em sistemas agroflorestais na região tropical: funcionalidade e sustentabilidade. In: Anais do Congresso Brasileiro de Sistemas Agroflorestais, Tendência da Agricultura Ecológica nos Trópicos: Sustento de Vida e Sustento da Vida. 2004; Ilhéus. Campos: Sociedade Brasileira de Sistemas Agroflorestais; Universidade Estadual do Norte Fluminense; 2004. p. 67-77.

Girardi E. Não é necessário derrubar mais nenhuma árvore não só na Amazônia como em nenhum outro bioma [online]. [cited 2009 abr. 15]. Available from: http://amazônia.org.br.

Golley FB. Tropical rain forest ecosystems: structure and function. Amsterdam: Elsevier; 1983.

Gomes MAO, Souza AVA, Carvalho RS. Diagnóstico rápido participativo (DRP) como Mitigador de impactos sócios-econômicos em empreendimentos agropecuários. Informe Agropecuário 2000; 21(202):110119.

Götsch E. O renascer da agricultura. Rio de Janeiro: ASPTA; 1996.

Instituto Brasileiro de Geografia e Estatística - IBGE. Projeto Radam Brasil. Folha SB 22 Araguaia e parte da folha SC 22 Tocantins. Levantamento de recursos naturais [CD-ROM]. 2003. v. 4.
Leão AL, Engel VL. Balanço de carbono em SAF's Argumentos para a redução do efeito estufa. In: Anais do Congresso Brasileiro de Sistemas Agroflorestais, Tendência da Agricultura Ecológica nos Trópicos: Sustento de Vida e Sustento da Vida. 2004; Ilhéus. Campos: Sociedade Brasileira de Sistemas Agroflorestais, Universidade Estadual do Norte Fluminense; 2004. p. 63-64.

Luizão FJ, Schubart HOR. Litter production and decomposition in a terra-firme florest of Central Amazonia. Experientia 1987; 43(3):259-265.

Magalhães LMS, Blum WEH. Distribuição radicular de espécies plantadas na região de Manaus, Amazônia. Floresta e Ambiente 2000; 7(1):93-103.

Marques JDO, Libardi PL, Teixeira WG, Reis AM. Estudos de parâmetros físicos, químicos e hídricos de um Latossolo Amarelo, na região Amazônica. Acta Amazônica 2004; 34(2):145-154.

Martins PFS, Volkoff B, Cerri CC, Andreux F. Consequências do cultivo e do pousio sobre a matéria orgânica do solo sob floresta natural na Amazônia Oriental. Acta Amazonica 1990; 20(1): 19-28.

Moreira A, Costa DG. Dinâmica da matéria orgânica na recuperação de clareiras da Floresta Amazônica. Pesquisa Agropecuária Brasileira 2004; 39(10):11031110.

Nye PH. Organic matter and nutrient cycles under moist tropical forest. Plant and Soil 1961; 13(4):333-346.

Primavesi A. Manejo ecológico dos solos: a agricultura em regiões tropicais. 7. ed. São Paulo: Nobel; 1994.

Rheinheimer DS, Kaminski J, Lupatini GC, Santos EJC. Modificações em atributos químicos de solos arenoso sob plantio direto. Revista Brasileira de Ciência do Solo 1998; 22:713-721.

Ribaski J, Montoya LJ, Rodigheri HR. Sistemas Agroflorestais: aspectos ambientais e socioeconômicos. Informe Agropecuário 2001; 22(212):61-67.

Santos AMG. Aproveitamento de resíduos das culturas de cupuaçu (Theobroma grandiflorum) e pupunha (Bactris gasipae) como adubo orgânico em sistemas agroflorestais na Amazônia [dissertação]. Manaus: Faculdade de Ciências Agrárias, Universidade Federal do Amazonas; 2003.

Santos GA, Silva LS, Canellas LP, Camargo FAO, editors. Fundamentos da matéria orgânica do solo. 2. ed. Porto Alegre: Grafica Metrópole; 2008.

Secretaria do Planejamento e Meio Ambiente. Atlas do Tocantins: subsídios ao planejamento da gestão territorial. Palmas: SEPLAN-DEZ; 1999.

Silva PPV. Sistemas agroflorestais para a recuperação de matas ciliares em Piracicaba SP [dissertação]. 
Piracicaba: Escolar Superior de Agricultura Luís de Queiroz, Universidade de São Paulo; 2002.

Vital ART, Guerrini IA, Franken WK. Produção de serapilheira e ciclagem de nutrientes de uma floresta semidecidual em zona ripária. Revista Árvore 2004; 28(6):847-853.
Zech W, Senesi N, Guggenberger G, Kaiser K, Lehman $\mathrm{J}$, Miano $\mathrm{T}$ et al. Factors controlling humification and mineralization of soil organic matter in the tropics. Geoderma 1997; 79(4):117-161. doi:10.1016/S00167061(97)00040-2 